\title{
Types of Feeding and Presence of Harmful Oral Habits in Children with Cleft Lip and/or Palate: A Pilot Study
}

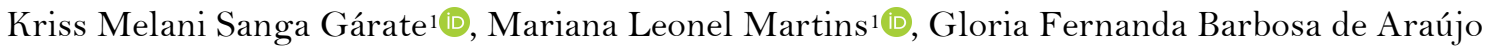 \\ Castro $^{1}$, Beatriz Costa $^{2}(0)$
}

\begin{abstract}
${ }^{1}$ Department of Pediatric Dentistry and Orthodontics, School of Dentistry, Federal University of Rio de Janeiro, Rio de Janeiro, RJ, Brazil.

${ }^{2}$ Hospital for Rehabilitation of Craniofacial Anomalies, Bauru School of Dentistry, University of São Paulo, Bauru, SP, Brazil.
\end{abstract}

Author to whom correspondence should be addressed: Gloria Fernanda Barbosa de Araújo Castro, Rua Rodolpho Paulo Rocco 325, Cidade Universitária, Rio de Janeiro, RJ, Brazil. 21941-913. Phone: +55 2139382101. E-mail: gfbacastro@yahoo.com.br.

Academic Editor: Catarina Ribeiro Barros de Alencar

Received: 29 March 2020 / Accepted: 25 May 2020 / Published: 04 August 2020

How to cite this article: Gárate KMS, Martins ML, Castro GFBA, Costa B. Types of feeding and presence of harmful oral habits in children with cleft lip and/or palate: a pilot study. Pesqui Bras Odontopediatria Clín Integr. 2020; $20: e 0063$. https://doi.org/10.1590/pboci.2020.154

\begin{abstract}
Objective: To verify the relationship between the types of feeding and presence of harmful oral habits $(\mathrm{HOH})$ in children with cleft lip (CL), palate (CP) and cleft lip and palate (CLP), as well as to compare the different types of cleft to each other. Material and Methods: A form was applied to the parents of 162 children (3-5 years old), addressing the following variables: gender, cleft type, age, socioeconomic conditions, type of breastfeeding, presence of $\mathrm{HOH}$, and the parents' knowledge about the consequences of oral habits. The data obtained were analyzed by chi-square test $(\mathrm{p}<0.05)$. Results: The majority of children $(83.3 \%)$ were bottle-fed and $12.3 \%$ were exclusively maternal breastfed. The main reason for weaning was the presence of cleft $(59.9 \%)$. Breastfeeding was significantly higher in children with CL (75\%) in comparison with CP $(20 \%)$ and CLP $(5 \%)(\mathrm{p}<0.001)$. Children with CLP were 12 times more likely to be bottle-fed than children with $\mathrm{CL}(\mathrm{OR}=12.21 ; \mathrm{CI}=4.09-36.45)$. The prevalence of $\mathrm{HOH}$ was $37 \%$. Sociodemographic characteristics were not associated with the presence of $\mathrm{HOH}(p>0.05)$. The type of feeding and cleft were not decisive to present some type of $\mathrm{HOH}(\mathrm{p}>0.05)$ and $87 \%$ of parents stated that $\mathrm{HOH}$ could lead to serious complications of tooth misalignment. Conclusion: The type of feeding and fissure did not determine the acquisition of harmful oral habits in children with cleft. However, the greater the fissure's complexity, the lesser the chance of children receiving exclusive breastfeeding.

Keywords: Breast Feeding; Habits; Pacifiers; Cleft Lip; Cleft Palate.
\end{abstract}




\section{Introduction}

Breast milk is the main source of nutrition, which aims at the survival of the baby [1,2], meeting all nutritional needs [3-5] and promoting the affective bond between mother and child, which helps to build a suitable environment for the child [6]. In addition, it plays a very important role in the proper development of dentofacial structures and their functions [4], contributing to maxillary growth [7], harmonic development of dental arches and reducing the risk of acquiring some type of malocclusion [8,9].

The difficulty of breastfeeding may be due to several reasons: insufficient milk, mothers' work activity, greater comfort in the use of artificial milk, among others $[1,4,10]$. Often, breastfeeding is replaced by bottle feeding, which consequently requires the movement of fewer muscles compared to breastfeeding, capable of promoting adequate muscle activity, leading to the optimal development of bucomotor structures [11].

The sucking habit is a normal reflex present since the 29 th week of intrauterine life [5,10]. It is considered an acceptable habit until three years old, being a natural part of the child's development and dentofacial strengthening [3]. If the oral habit is not discontinued at this age, it may cause oral damage such as morphological alteration in the palate, malocclusion (anterior open bite, and posterior crossbite) and gingival changes $[8,9,12,13]$; also the severity of the damage is related to the frequency, duration and intensity of the oral habit [14].

Exclusive breastfeeding for at least six months may prevent the acquisition of some non-nutritive sucking habits, but periods shorter than six months may represent a risk factor. Studies in the literature report that the longer the breastfeeding time, the lower the chance of the child having any type of oral habit $[5,6,12,15,16]$.

In individuals with cleft lip and / or palate, breastfeeding becomes more difficult due to anatomical discontinuity of the lip and / or palate, making it difficult to establish the negative pressure necessary for sucking [17], which could cause a higher frequency of harmful oral habits $(\mathrm{HOH})$. However, studies in the population of children with cleft of lip and/or palate regarding oral habits are scarce.

Therefore, this paper aims to investigate the association between type of feeding and the prevalence of $\mathrm{HOH}$ in children with cleft lip and/or palate, document the prevalence of habits in this specific population, and compare the different types of cleft to each other.

\section{Material and Methods}

Study Design and Sample

This is a cross-sectional and descriptive pilot study, carried out with a non-probabilistic sample of children aged 3 to 5 years, of both genders, submitted to cleft surgery of lip and/or palate and non-syndromic.

\section{Data Collection}

The research instrument consisted of a specific form for parents applied in the form of an interview, which addressed the following variables: gender, cleft type, age group, socioeconomic conditions, type of feeding and presence of $\mathrm{HOH}$ (as biting nails, pacifier sucking, finger sucking, lip and tongue interposition) of the child.

Data on socioeconomic status were obtained from the patient's medical records, according to the following classification, which considers six categories: Lower-Lower (F), Lower-Upper (E), Lower-Middle (D), Middle (C), Upper-Middle (B) and High (A) [18]. The classification had the family as its central nucleus, more specifically its living conditions. Therefore, it was considered socio-analytical information about their 
income, occupational activity that their members perform, family demographic composition, educational level and housing conditions [18]. In addition, it was analyzed the parents' knowledge about the consequences of oral habits.

\section{Data Analysis}

The obtained data were organized and analyzed in the Statistical Package for Social Science, version 20.0 (SPSS for Windows, Chicago, USA). To verify the association between the studied variables, were used the Chi-square test and crude odds ratios (OR) with 95\% confidence intervals (CI) and significance level of $\mathrm{p}<0.05$, respectively.

Ethical Aspects

The study was approved by the ethics committee of Hospital for Rehabilitation of Craniofacial Anomalies, University of São Paulo (Process No. 39216514.3 .0000 .5441 ).

\section{Results}

A total of 162 children (79 females and 83 males) with a mean age of $4.40( \pm 0.70)$ were assessed and their respective parents were interviewed. According to the type of cleft, 50.6\% presented cleft lip and palate (CLP), 26.5\% cleft lip (CL) and 22.8\% presented cleft palate (CP). Regarding the type of feeding, $83.3 \%$ of the children received bottle-fed, $12.3 \%$ had exclusive breastfeeding and 4.4\% had another type of feeding (dropper or spoon). The presence of cleft was the main reason for the weaning reported by mothers $(59.9 \%)$. On the other hand, the prevalence of $\mathrm{HOH}$ in the evaluated population was $37 \%$, being nail-biting the most frequent (11.1\%) (Figure 1).

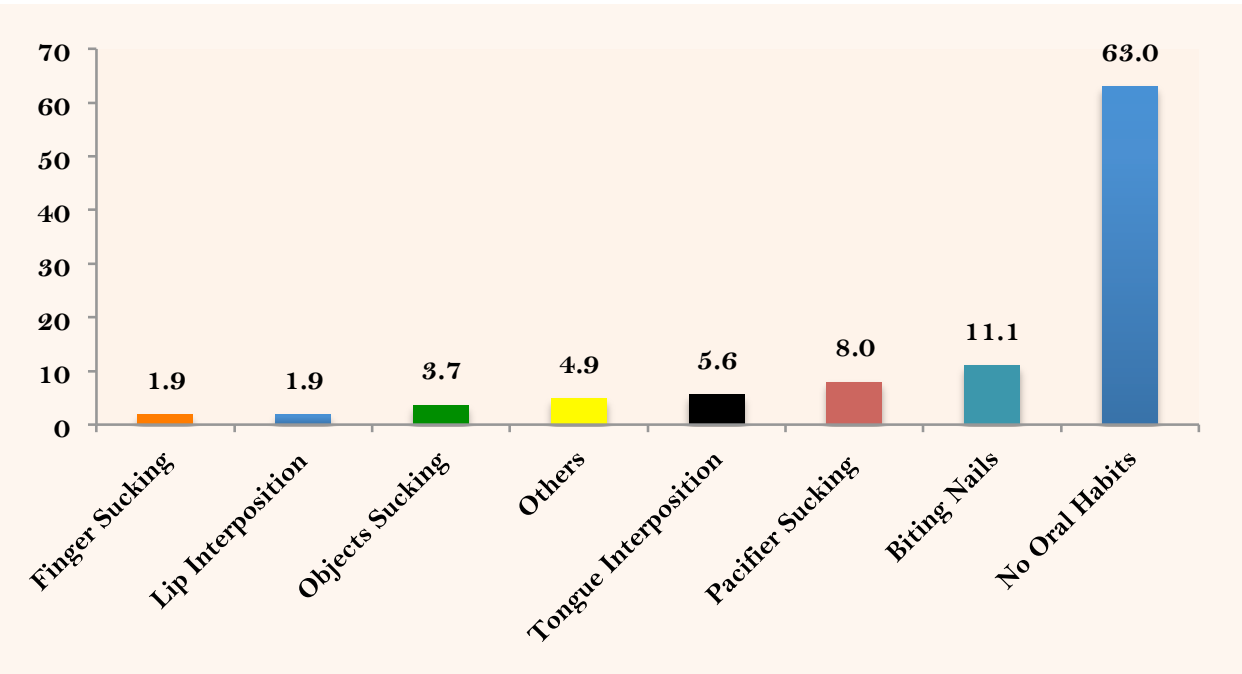

Figure 1. Frequency of harmful oral habits in children.

In the bivariate evaluation between the type of feeding and type of cleft, it was observed that bottle-fed was more prevalent in children with CLP (57.8\%), while breastfeeding was more prevalent in children with CL $(75 \%)$, which shows statistically significant differences $(\mathrm{p}<0.001)$. Children with CLP were 12 times more commonly bottle-fed than children with CL $(\mathrm{OR}=12.21$; CI $=4.09-36.45)$. On the other hand, there was no statistically significant association between the presence of $\mathrm{HOH}$ and the type of cleft $(\mathrm{p}=0.120)$ (Table 1). 
Table 1. Association between presence of harmful oral habits, breastfeeding type and types of cleft.

\begin{tabular}{|c|c|c|c|c|}
\hline \multirow[b]{2}{*}{ Variables } & \multicolumn{3}{|c|}{ Types of Cleft } & \multirow[b]{2}{*}{ p-value ${ }^{1}$} \\
\hline & $\begin{array}{c}\text { Lip } \\
\text { N (\%) }\end{array}$ & $\begin{array}{l}\text { Palate } \\
\text { N (\%) }\end{array}$ & $\begin{array}{c}\text { Lip and Palate } \\
\text { N (\%) }\end{array}$ & \\
\hline \multicolumn{5}{|c|}{ Presence of Harmful Oral Habits } \\
\hline Yes & $20(33.3)$ & $9(15.0)$ & $31(51.7)$ & 0.120 \\
\hline No & $23(22.5)$ & $28(27.5)$ & $51(50.0)$ & \\
\hline \multicolumn{5}{|l|}{ Feeding Type } \\
\hline Breast Milk & $15(75.0)$ & $4(20.0)$ & $1(5.0)$ & $0.001^{*}$ \\
\hline Baby Bottle & $27(20.0)$ & $30(22.2)$ & $78(57.8)$ & \\
\hline Others & $1(14)$ & $3(42.9)$ & $3(42.9)$ & \\
\hline
\end{tabular}

${ }^{\mathrm{I}}$ Chi-squared test; *Statistically Significant.

No statistically significant differences were observed between the presence of $\mathrm{HOH}$ and sociodemographic variables such as age, gender, socioeconomic level and parental education ( $p>0.05)$. The type of feeding and duration of breastfeeding were not associated with the presence of HOH (Table 2). When analyzing parents' knowledge about $\mathrm{HOH}, 58.6 \%$ answered that the type of feeding does not influence the acquisition of oral habits. However, $87 \%$ of parents stated that $\mathrm{HOH}$ could lead to serious complications of tooth misalignment.

Table 2. Association between presence of harmful oral habits and sociodemographic factors.

\begin{tabular}{|c|c|c|c|}
\hline \multirow{3}{*}{ Variables } & \multicolumn{3}{|c|}{ Presence of Harmful Oral Habits (HOH) } \\
\hline & Yes & No & p-value ${ }^{1}$ \\
\hline & $\mathrm{N}(\%)$ & $\mathrm{N}(\%)$ & \\
\hline \multicolumn{4}{|l|}{ Gender } \\
\hline Male & $34(56.7)$ & $49(48.0)$ & 0.369 \\
\hline Female & $26(43.3)$ & $53(52.0)$ & \\
\hline \multicolumn{4}{|l|}{ Age } \\
\hline 3 Years & $7(11.7)$ & $14(13.9)$ & 0.746 \\
\hline 4 Years & $19(31.7)$ & $36(35.6)$ & \\
\hline 5 Years & $34(56.7)$ & $51(50.5)$ & \\
\hline \multicolumn{4}{|l|}{ Caregiver's Educational Level } \\
\hline Elementary School & $11(18.3)$ & $27(26.5)$ & 0.409 \\
\hline High School & $30(50.0)$ & $50(49.0)$ & \\
\hline Higher Education Level & $19(31.7)$ & $25(24.5)$ & \\
\hline \multicolumn{4}{|l|}{ Socioeconomic Status } \\
\hline A & $13(21.7)$ & $27(26.5)$ & 0.611 \\
\hline $\mathrm{B}$ & $40(66.7)$ & $60(58.8)$ & \\
\hline $\mathrm{C}$ & $7(11.7)$ & $14(13.7)$ & \\
\hline $\mathrm{D}$ & $\mathrm{o}(0.0)$ & $1(1.0)$ & \\
\hline \multicolumn{4}{|l|}{ Feeding Type } \\
\hline Breast Milk & $4(6.7)$ & $16(15.7)$ & 0.201 \\
\hline Baby Bottle & $54(90.0)$ & $81(79.4)$ & \\
\hline Others & $2(3.3)$ & $5(4.9)$ & \\
\hline \multicolumn{4}{|l|}{ Breastfeeding Duration } \\
\hline$<6$ Months & $21(70)$ & $27(54.0)$ & 0.239 \\
\hline$\geq 6$ Months & $9(30)$ & $23(46.0)$ & \\
\hline
\end{tabular}

\section{Discussion}

The present study revealed a high prevalence of artificial feeding in children with a cleft (83.3\%) and a low prevalence of exclusive breastfeeding (12.3\%), similar results were found in a study carried out with 
Brazilian children [17]. The presence of cleft was the main reason for weaning children reported by parents, agreeing with previous studies [17,19], but these differ from the results found in Brazilian babies without cleft, where the main cause for weaning is mother's return to work (20.9\%), followed by lack of milk (19.4\%) [4]. In our study, these causes were also reported, but in a lower percentage (6.8\% and $4.9 \%$, respectively).

Regarding the type of cleft, this study revealed that the more complex the cleft (CLP), the greater is the degree of difficulty for breastfeeding. In this sense, it was observed that children with isolated CL were more favored for breastfeeding compared to children with CP or CLP, agreeing with a previous study [20]. The difficulties of breastfeeding babies with palatal cleft involvement could occur due to anatomical changes, presenting communication between the oral and nasal cavities. This leads to poor suction because is not possible to establish adequate intraoral negative pressure for breast milk suction $[17,19]$.

A prevalence of $\mathrm{HOH}$ in children without cleft is verified by various studies in the literature $[4,6,15,16,21,22]$, which showed that the longer duration of exclusive breastfeeding, lower the chance of to present $\mathrm{HOH}$; showing an association between breastfeeding and $\mathrm{HOH}$. In the present study, a higher frequency of $\mathrm{HOH}$ was observed among children who were breastfed for less than six months. However, there was no statistically significant difference, possibly due to the sample size. Therefore, future studies with larger numbers of individuals are suggested to confirm this tendency. Furthermore, in this study, although there was a low percentage of children with cleft breastfeeding, there was also a low prevalence of $\mathrm{HOH}(37 \%)$ when compared to studies done in children without clefts $(81.5 \%$ [23] and $61.8 \%$ [24] $)$ who did not have exclusive breastfeeding.

According to type of habit, biting nails was the most frequently reported $(11.1 \%)$, whereas finger sucking was the least frequent (1.9\%). A previous study reported a lower prevalence of pacifier sucking (2.7\%) and a higher prevalence of other oral habits in children with cleft [25]. In the present study, a prevalence de pacifier sucking was $8.0 \%$.

Nevertheless, another pilot study reported an occurrence of thumb and finger sucking of $26.9 \%$ among children with cleft, however, this was not statistically significant when compared to children without cleft [26]. Thus, there was a higher percentage of finger sucking compared with our study. A possible reason for this result would be that in the hospital early lip and palate repair surgery that is performed, before the age of three, where which the parents are advised by the plastic surgeon and pediatric dentist to prevent the child uses a pacifier or performs finger suction, in order to obtain good postoperative results avoiding risks of infection or trauma in closing the cleft being beneficial for not presenting oral habits.

The correlation between $\mathrm{HOH}$ and gender was not statistically significant in the present study, as observed by other authors in Brazilian children from 3 to 6 years old [27]. However, it differed from other studies conducted in Brazilian children without cleft between ages 2 to 5 years that found an association between non-nutritive sucking habits and females $[6,9,16]$; according to these authors, there is no consensus in the scientific literature to explain the higher prevalence of habits among girls and therefore suggest the need for investigations into psychological differences between genders. Similarly, in this study was not observed a significant correlation between age and $\mathrm{HOH}$. However, it is known that increasing age leads to a reduction in sucking habits [28] and, therefore, would be an orthodontically relevant factor, since occlusal damage, such as open bite treated early in the deciduous or mixed dentition decreases the chance of recurrence [29].

In the present study, the socioeconomic indicator and parents' education also showed no significant association with $\mathrm{HOH}$. However, it can be observed that there are controversies in the literature. It was reported that children whose parents have a higher level of education present a higher risk of prolonged 
pacifier sucking [3,6]. Similarly, the high family income has shown a high relationship with the pacifier habit. On the other hand, previous authors observed that most mothers or caregivers of children who presented nonnutritive sucking habits also had low family income (70.6\%) [4]. The non-association results of the present study could be because regular patients formed the total population from the pediatric dental department of the hospital where they received specialized dental care and informative talks according to each one's needs. Therefore, this can be considered a protective factor for $\mathrm{HOH}$ in this population group.

The assessment of parental knowledge about $\mathrm{HOH}$ showed that $41.4 \%$ were unaware of a relationship between type of feeding and oral habits. However, most of them mentioned the relationship between habits and the development of serious complications of tooth misalignment (87\%). A similar result was obtained by previous authors that found that $97.1 \%$ of parents knew that habits could cause damage to teeth [30]. This knowledge of parents may be due to the frequent guidance that parents of children receive on each dental checkup at the hospital.

Finally, these results cannot be generalized due to cultural and socioeconomic factors. Therefore, these observations point to the need to conduct studies with larger samples to verify the present data.

These results highlight the importance of early intervention in the dental clinic during the care of babies with cleft lip and / or palate, through guidance to parents about the importance of breastfeeding, which should be performed whenever possible. However, when the child already has $\mathrm{HOH}$, the pediatric dentist should inform parents about the risks of damage to the child's occlusion if the deleterious habit is not eliminated in a period of 3 years, due to the fact that it increases the probability of alterations significantly not only in occlusion but also in speech and breathing [3]. Therefore, the presence of habits should be monitored to prevent them from becoming deleterious.

\section{Conclusion}

The type of feeding and cleft did not determine the acquisition of harmful oral habits in children with cleft. However, the greater the complexity of the fissure, the lesser the chance of the child receiving exclusive breastfeeding.

\section{Authors' Contributions}

$\begin{array}{lll}\text { KMSG (D) 0000-0001-5513-9905 } & \begin{array}{l}\text { Conceptualization, Methodology, Investigation and Writing - Original Draft } \\ \text { Preparation. }\end{array} \\ \begin{array}{lll}\text { MLM } & \text { (D) } 0000-0001-6777-3225 & \text { Writing - Original Draft Preparation and Writing - Review and Editing. } \\ \text { GFAC } & \text { (D) 0000-0002-8137-0307 } & \text { Writing - Original Draft Preparation and Writing - Review and Editing. } \\ \text { BC } & \text { (D) } 0000-0002-7917-3072 & \text { Conceptualization, Methodology and Formal Analysis. } \\ \text { All authors declare that they contributed to critical review of intellectual content and approval of the final version to be } \\ \text { published. }\end{array}\end{array}$

\section{Financial Support}

None

\section{Conflict of Interest}

The authors declare no conflicts of interest.

\section{References}

[1] Caglar E, Larsson E, Andersson EM, Hauge MS, Ogaard B, Bishara S, et al. Feeding, artificial sucking habits, and malocclusions in 3-year-old girls in different regions of the world. J Dent Child 2005; 72(1):25-30. 
[2] Sabuncuoglu O. Understanding the relationship between breastfeeding, malocclusion, ADHD, sleep-disordered breathing and traumatic dental injuries. Med Hypotheses 2013; 80(3):315-20. https://doi.org/10.1016/j.mehy.2012.12.017

[3] Santos SA, Holanda ALF, Sena MF, Gondim LAM, Ferreira MAF. Nonnutritive sucking habits among preschool aged children. J Pediatr 2009; 85(5):408-14. https://doi.org/10.2223/jped.1926

[4] Moimaz SAS, Rocha NB, Garbin AJI, Saliba O. The relation between maternal breast feeding and non-nutritive sucking habits. Cien Saude Coletiva 2011; 16(5):2477-84. https://doi.org/10.1590/s1413-81232011000500017

[5] Bueno SB, Bittar TO, Vazquez FL, Meneghim MC, Pereira AC. Association of breastfeeding, paciefier use, breathing pattern and malocclusions preschoolers. Dental Press J Orthod 2013; 18(1):30.e1-6. https://doi.org/10.1590/s2 176-94512013000100006

[6] Holanda ALF, Santos SA, Sena MF, Ferreira MAF. Relationship between breast- and bottle-feeding and nonnutritive sucking habits. Oral Health Prev Dent 2009; 7(4):331-7. https://doi.org/10.3290/j.ohpd.a18083

[7] Jabbar NSA, Bueno ABM, Silva PE, Scavone-Junior H, Ferreira RI. Bottle feeding, increased overjet and Class 2 primary canine relationship: is there any association? Braz Oral Res 2011; 25(4):331-7. https://doi.org/10.1590/s1806-83242011000400009

[8] Karjalainen S, Rönning O, Lapinleimu H, Simell O. Association between early weaning, non- nutritive sucking habits and occlusal anomalies in 3 year-old Finnish children. Int $\mathrm{J}$ Paediatr Dent 1999; 9(3):169-73. https://doi.org/10.1046/j.1365-263x.1999.00133.x

[9] Vasconcelos FMN, Massoni ACLT, Heimer MV, Ferreira AMB, Katz CRT, Rosenblatt A. Non-nutritive sucking habits, anterior open bite and associated factors in Brazilian children aged 30-59 months. Braz Dent J 2011; 22(2):140-5. https://doi.org/10.1590/s0103-64402011000200009

[10] Satyaprasad S. Anunusual type of sucking habit in a patient with cleft lip and palate. J Indian Soc Pedod Prev Dent 2009; 27(4):260-2. https://doi.org/10.4103/0970-4388.57664

[11] Barbosa C, Vasquez S, Parada MA, Gonzalez JCV, Jackson C, Yanez ND, et al. The relationship of bottle feeding and other sucking behaviors with speech disorder in Patagonian preschoolers. BMC Pediatr 2009; 9:66. https://doi.org/10.1186/1471-2431-9-66

[12] Moimaz SAS, Saliba O, Lolli LF, Garbin CAS, Garbin AJI, Saliba NA. A longitudinal study of the association between breast feeding and harmful oral habits. Pediatr Dent 2012; 34(2):117-21.

[13] Romero CC, Scavone-Jr H, Garib DG, Cotrim-Ferreira FA, Ferreira RI. Breastfeeding and non-nutritive sucking patterns related to the prevalence of anterior open bite primary dentition. J Appl Oral Sci 2011; 19(2):161-8. https://doi.org/10.1590/s1678-77572011000200013

[14] Castilho SD, Rocha MAM. Pacifier habit: history and multidisciplinary view. J Pediatr 2009; 85(6):480-9. https://doi.org/10.2223/jped.1951

[15] Telles FBA, Ferreira RI, Magalhães LNC, Scavone-Junior H. Effect of breast- and bottle-feeding duration on the age of pacifier use persistence. Braz Oral Res 2009; 23(4):432-8. https://doi.org/10.1590/s 1806-83242009000400013

[16] Lopes TSP, Moura LFAD, Lima MCMP. Breastfeeding and sucking habits in children enrolled in a mother- child health program. BMC Res Notes 2014; 7:362. https://doi.org/10.1186/1756-0500-7-362

[17] Dalben GS, Costa B, Gomide MR, Neves LT. Breast-feeding and sugar intake in babies with cleft lip and palate. Cleft Palate Craniofac J 2003; 4O(1):84-7. https://doi.org/10.1597/1545-1569_2003_040_0084_bfasii_2.0.co_2

[18] Graciano MIG, Lefeld NAS. Estudo socioeconômico: indicadores e metodologia numa abordagem contemporânea. Serviço Social e Saúde 2010; 9(1):157-86. https://doi.org/10.20396/sss.v9i1.8634873 [In Portuguese]

[19] Goyal A, Jena AK, Kaur M. Nature of feeding practices among children with cleft lip and palate. J Indian Soc Pedod Prev Dent 2012; 30(1):47-50. https://doi.org/10.4103/0970-4388.95581

[20] Garcez LW, Giugliani ER. Population-based study on the practice of breastfeeding in children born with cleft lip and palate. Cleft Palate Craniofac J 2005; 42(6):687-93. https://doi.org/10.1597/04-108r 1.1

[21] Albuquerque SSL, Duarte RC, Cavalcanti AL, Beltrão EM. The influence of feeding methods in the development of non-nutritive sucking habits in chidhood. Cienc Saude Coletiva 2010; 15(2):371-8.

https://doi.org/10.1590/S1413-81232010000200012

[22] Chen X, Xia B, Ge L. Effects of breast-feeding duration, bottle-feeding duration and non-nutritive sucking habits on the occlusal characteristics of primary dentition. BMC Pediatr 2015; 15:46.

https://doi.org/10.1186/s12887-015-0364-1

[23] Lopes-Freire GM, Cárdenas ABC, Deza JEES, Ustrell-Torrent JM, Oliveira LB, Quesada Jr JRB. Exploring the association between feeding habits, non-nutritive sucking habits, and malocclusions in the deciduous dentition. Prog Orthod 2015; 16:43. https://doi.org/10.1186/s40510-015-0113-x

[24] Ozawa, N, Hamada, S, Takekoshi, F, Shinji H. A study on non-nutritive sucking habits in young Japanese children. Pediatr Dent J 2005; 15(1):64-71. https://doi.org/10.1016/S0917-2394(05)70031-8

[25] Barsi PC, Silva TR, Costa B, Dalben GS. Prevalence of oral habits in children with cleft lip and palate. Plast Surg Int 2013; 2013:247908. https://doi.org/10.1155/2013/247908

[26] Alighieri C, Bettens K, Bonte K, Roche N, Van Lierde K. Oral habits in children with cleft (lip and) palate: a pilot study. Folia Phoniatr Logop 2019; 71(4):191-6. https://doi.org/10.1159/000495611 
[27] Scavone-Jr H, Guimarães-Jr CH, Ferreira RI, Nahás ACR, Vellini-Ferreira F. Association between breastfeeding duration and non-nutritive sucking habits. Community Dent Health 2008; 25(3):161-5. https://doi.org/10.1922/CDH_2091-Scavone05

[28] Jajoo S, Chunawala Y, Bijle MN, Shah R, Kamble A, Gaonkar NK. oral habits in school going children of Pune: a prevalence study. J Int Oral Health 2015; 7(10):96-101.

[29] Ngan P, Fields HW. Open bite: a review of etiology and management. Pediatr Dent 1997; 19(2):91-8.

[30] Garbin CAS, Garbin AJI, Martins RJ, Souza NP, Moimaz SAS. Prevalence of non-nutritive sucking habits in preschoolers and parents' perception of its relationship with malocclusions. Cienc Saude Coletiva 2014; 19(2):553-8. https://doi.org/10.1590/1413-81232014192.23212012 